\title{
Assessment of Scientific Production of the Health Sciences University on Oral Submucous Fibrosis Using Bibliometric Analysis
}

\author{
Roshan Umate ${ }^{1}$, Manoj Patil ${ }^{2}$, Shital Telrandhe ${ }^{3}$, Aniket Pathade ${ }^{4}$, \\ Kumar Gourav Chhabra5 ${ }^{5}$ Gargi Nimbulkar ${ }^{6}$, Punit Fulzele $^{7}$
1, 2, 3, 4 Department of Research and Development, Jawaharlal Nehru Medical College, Datta Meghe Institute of Medical Sciences, Sawangi (Meghe), Wardha, Maharashtra, India. 5, 6 Department of Public Health Dentistry, Sharad Pawar Dental College and Hospital, Datta Meghe Institute of Medical Sciences, Sawangi (Meghe), Wardha, Maharashtra, India. ${ }^{7}$ Department of Pedodontics, Sharad Pawar Dental College and Hospital, Datta Meghe Institute of Medical Sciences, Sawangi (Meghe), Wardha, Maharashtra, India.

\section{ABSTRACT}

\section{BACKGROUND}

Oral submucous fibrosis is being recognized now as a chronic, insidious, premalignant condition affecting the mucosa of oral cavity, pharynx and the portion of upper oesophagus. Characteristically, it shows epithelial and sub-epithelial inflammation followed by fibro-elastic alterations in sub-mucosal region thereby leading to difficulty in opening mouth. Thus, stiffness of oral mucosa causes trismus and inability to eat. If untreated at earliest, it can progress to squamous cell carcinoma. Wardha is the smallest district in Maharashtra and a significant number of cases of oral submucous fibrosis and oral cancer are reported at the tertiary care hospital of the Health Sciences University. This study was conducted to shed light on the Scientific Productions of this Health Sciences University in Central India regarding cancers and oral submucous fibrosis over the period of last 15 years.

\section{METHODS}

The Scopus and Web of Science databases were accessed, and the publications affiliated to the University were retrieved using the specified search query. The publications thus accessed were imported as BibText and RIS files and checked for duplicates in both databases. Duplicates were removed, and the final list of publications was prepared. Data related to finalised publications was imported to RStudio application for producing the graphs and plots related to the number of scientific productions.

\section{RESULTS}

The search generated a data of a total of 191 documents from 71 Sources (Journals, Books, etc.) for the period from 2007 - 2020. The number of authors included a list of 1356 authors. Authors of single-authored documents were 6; whereas, authors of multi-authored documents were 1350 . Thus, there were 7.1 authors per document, 9.13 co-authors per document. The Collaboration Index was 7.3. Average citations per document was 37 .

\section{CONCLUSIONS}

The university has contributed significantly to the scientific literature on oral submucous fibrosis.

\section{KEY WORDS}

Oral Submucous Fibrosis, Oral Cancer, Bibliometric, Scientific Production, University
Corresponding Author:

Dr. Manoj Patil.

Department of Research and Development, Jawaharlal Nehru Medical

College, Datta Meghe Institute of Medical

Sciences, Sawangi (Meghe), Wardha,

Maharashtra, India.

E-mail: drmanojpatil1979@gmail.com

DOI: $10.14260 /$ jemds/2020/665

How to Cite This Article:

Umate $R$, Patil $M$, Telrandhe $S$, et al. Assessment of scientific production of the health sciences university on oral submucous fibrosis using bibliometric analysis. J Evolution Med Dent Sci 2020;9(41):3033-3039, DOI: $10.14260 /$ jemds/2020/665

Submission 07-02-2020,

Peer Review 02-09-2020,

Acceptance 08-09-2020,

Published 12-10-2020.

Copyright (C) 2020 Roshan Umate et al. This is an open access article distributed under Creative Commons Attribution License [Attribution 4.0 International (CC BY 4.0)] 


\section{BACKGROUND}

Oral submucous fibrosis is being recognized now as a chronic, insidious, premalignant condition, affecting the mucosa of oral cavity, pharynx, and the portion of upper oesophagus. Characteristically, it shows epithelial and sub-epithelial inflammation followed by fibro-elastic alterations in submucosal region thereby leading to difficulty in opening mouth. The stiffness of oral mucosa causes trismus and inability to eat. ${ }^{1}$

Joshi was the first person in India who reported OSMF in 1953. He reported the terms submucous fibrosis of faucial pillars and soft palate. ${ }^{2}$ Some other terms were also coined like diffuse oral submucous fibrosis by Lal in 1953, idiopathic scleroderma of the mouth by $\mathrm{Su}$ in 1954, idiopathic palatal fibrosis by Rao in 1962 and sclerosing stomatitis by Behl in 1962.2

OSMF is a most common condition reported among the South East Asians and Indian population. ${ }^{3}$ Indian population showed the highest rate of incidence. Incidence of 2.6 per 100,000 per year among males and an 8.5 per 100,000 per year among females, was reported from North Western India. Incidence from Southern India was reported to be 9 and 20 per 100,000 per year for males and females, respectively. 4,5

In India, the prevalence of OSMF was estimated to be 5 million in 2002,.6 As per the recent reports, prevalence in India has shown to be increased from 0.03 to $6.42 \% .^{7}$

Sinor et $\mathrm{al}^{8}$ and Kumar et $\mathrm{al}^{9}{ }^{9}$ reported OSMF to be predominant among males. Wide variation in ages were reported by various authors. Pindborg et $\mathrm{al}^{5}$ reported that an average age range for males was 53.6 years and for females, it was 37.7 years. As per the study by Babu et al, ${ }^{10}$ and Trivedy et al,11 $23 \%$ of patients belonged to 14 to 19 years age group. Other authors reported that incidence of OSMF was higher in younger populations and age ranges from 20 to 30 years. ${ }^{12}$

Oral Submucous Fibrosis (OSMF) was labelled as "Atropica Idiopathica Mucosae Oris" by Schwartz in 1952. He described OSMF as the potentially malignant disorder. In the year 1966, Jens J. Pindborg described it as a chronic insidious disease involving oral tissues, the pharynx and sometimes accompanied with formation of vesicles. Histopathologically, it shows epithelial atrophy with a juxta-epithelial inflammatory reaction and fibroelastic change of the lamina propria leading to stiffness of the oral mucosa. This causes restricted mouth opening resulting in trismus and difficulty in eating. 13

Characteristics of OSMF are 1] reduced movement accompanied with loss of tongue papillae, 2] paleness / blanching of the oral mucosa with leather like texture, 3] restricted mouth opening, 4] shrinking of uvula. ${ }^{14-16}$

Some authors described OSMF as idiopathic (aetiology unknown) scleroderma of oral tissues, fibrosis of juxtaepithelial tissue, palatal fibrosis due to unknown cause, and sclerosing stomatitis". 15-18

Although a number of cases finding surveys were conducted throughout India, OSMF is not a well-recognized, notified condition and very few population-based datasets are disseminated. ${ }^{19}$ The estimated prevalence of oral submucous fibrosis in India was in the range of $0.2-2.3 \%$ among males and $1.2-4.6 \%$ among females. Widespread marketing of various commercial tobacco and areca nut products, called Gutkha, resulted in marked increase in the incidence of oral submucous fibrosis. Consumption of areca nut is estimated to be around $20 \%$ of the population throughout the World in different forms and products.

OSMF is classified as a potential malignant disorder and cases affected with OSMF are reported to be highly vulnerable to the risk of developing oral squamous cell carcinoma. ${ }^{20-21} \mathrm{As}$ per a longitudinal study carried out over 17 years till 1970, 7.6 $\%$ of oral submucous fibrosis cases progressed to frank squamous cell carcinoma. Few other studies reported the rates of malignant transformation ranging from $1.9-9 \%$.

As per a retrospective study from China, oral cancer originating from oral submucous fibrosis was found clinically more invasive with higher potential of metastasis and recurrence rates compared to conventional oral squamous cell carcinoma. But, as per the studies by Chaturvedi et al., oral cancers arising from oral submucous fibrosis are less aggressive compared to the conventional tobacco-related oral cancers generally reported in India. Characteristically, oral cancers arising from oral submucous fibrosis were in early tumor stage, showed smaller and thin lesions, lesser metastases to neck with limited evidence of extra-capsular spread. The neoplastic lesions are quite well-differentiated. It was estimated that fibrosis results in reduced vascularity thus indirectly help to minimize the risk of spread of cancer through hematogenous and lymphatic routes.

Many studies reported higher risk of oral submucous fibrosis to get transformed into malignancy especially when it was accompanied with oral leukoplakia. A number of studies conducted in recent past focused on discovering the possible mechanisms of malignant transformation emphasized on "molecular markers" which seem to be quite sensitive armamentaria for early diagnosis of the lesions.

Measures to prevent OSMF includes public awareness about the ill-effects of betel nut and tobacco products along with strict legislations implemented to prohibit the sale of Gutkha and other tobacco products. ${ }^{22-23}$ Since May 2013, Gutkha is legally banned throughout major states and union territories of India, as per the "Food Safety and Regulation (Prohibition) Act 2011".

Wardha is the smallest district in Maharashtra and a significant number of cases of oral submucous fibrosis and oral cancer are reported at the tertiary care hospital of the Health Sciences University. This study was conducted to shed light on the Scientific Productions of the Health Sciences University in Central India regarding cancers and oral submucous fibrosis over the period of last 15 years.

\section{METHODS}

Scopus Database was accessed for the publications related to cancer and premalignant lesions and conditions with search query- "AF-ID (60094583)" and "submucous fibrosis" or "oral fibrosis" or "oral fibroses" or "atrophica idiopathica mucosae oris" or "palatal fibrosis" or "tongue fibosis" or "vidari" or "BFP" or "SSG" or "split screen graft" or "tongue flap" or "fibrotom" or "interpositional graft" or "platysma flap" or "collagen membrane" or "oral squamous cell carcinoma" or "malignancy" or "metastasis" or "sarcoma".

Similarly Web of Science database was accessed with specific search query of the Health Sciences University and KP $=$ (submucous fibrosis or oral fibrosis or oral fibroses or atrophica idiopathica mucosae oris or palatal fibrosis or 
palatal fibroses or tongue fibrosis or Vidari OR BFP or SSG or split screen graft or tongue flap or fibrotom or interpositional graft or platysma flap or collagen membrane or oral squamous cell carcinoma or malignancy or metastasis or sarcoma).

The publications thus accessed were imported as Bib-text and RIS files and checked for duplicates in both databases. The duplicates were removed, and the final list of publications was prepared. The data related to finalised publications was imported to R-Studio application for producing the graphs and plots related to number of scientific productions, co-author and keyword co-occurrences, most cited authors \& publications, factorial maps.

\begin{tabular}{|cc|}
\hline \multicolumn{2}{|c|}{ RESULT S } \\
\hline & \\
\hline Year & Articles \\
2007 & 1 \\
2008 & 6 \\
2009 & 10 \\
2010 & 9 \\
2011 & 15 \\
2012 & 15 \\
2013 & 8 \\
2014 & 12 \\
2015 & 14 \\
2016 & 12 \\
2017 & 18 \\
2018 & 18 \\
2019 & 14 \\
2020 & 39 \\
\hline Table 1. Year-Wise No. of Publications \\
\hline
\end{tabular}

The search generated the data of total 191 ddocuments from 71 Sources (Journals, Books, etc.) for the period from 2007 - 2020. The number of authors included a list of 1356 authors. Authors of single-authored documents were 6 whereas authors of multi-authored documents were 1350 . Thus, there were 7.1 authors per document, 9.13 co-authors per documents. The Collaboration Index was 7.3. Average citations per document was 37 .
The highest number of articles were 39 published in the year 2020 whereas lowest number of articles published was 1 in the year 2007. A steady progress can be seen in the scientific production over last 14 years with Annual Percentage Growth Rate of 32.55301 . Total 30 articles were found specifically written on oral submucous fibrosis and its associated factors.

\section{DISCUSSION}

From this Health Sciences University, there is a considerable rise in the publication on the topic oral sub mucous fibrosis within the past few years from 2007 to 2020 ranging from 1 to 39. Annual Percentage Growth Rate recorded is 32.55 . The average number of citations per document is 37. Total citations of published materials on Oral Sub Mucous Fibrosis show a distinguished rise in the recent years. The total citations of literature published in 2020 is 39 and further anticipated to point out sharp rise within the year 2020.

The list of all the authors was sorted out and from the list of around 1356 authors; the totality of the author appearances was 1743. Authors of multi-authored documents were 1350 . The Collaboration Index on the topic of oral sub mucous fibrosis was 7.3. The most productive, author had 36 articles to his credit. Top citations per manuscript was 65 citations and on an average per year it was 13 .

The list of most relevant sources included International Journal of Psychosocial Rehabilitation (33 articles), Journal of Datta Meghe Institute of Medical Sciences University (33 articles), Journal of Cancer Research And Therapeutics (10 articles), Journal of Oral And Maxillofacial Pathology (8 articles), Oral Oncology (8 articles), Journal of Clinical and Diagnostic Research (6 articles), Journal of Maxillofacial and Oral Surgery (5 articles), Journal of Oral Pathology and Medicine ( 5 articles), Journal of Contemporary Dental Practice (3 articles), Journal of Investigative and Clinical Dentistry (3 articles).

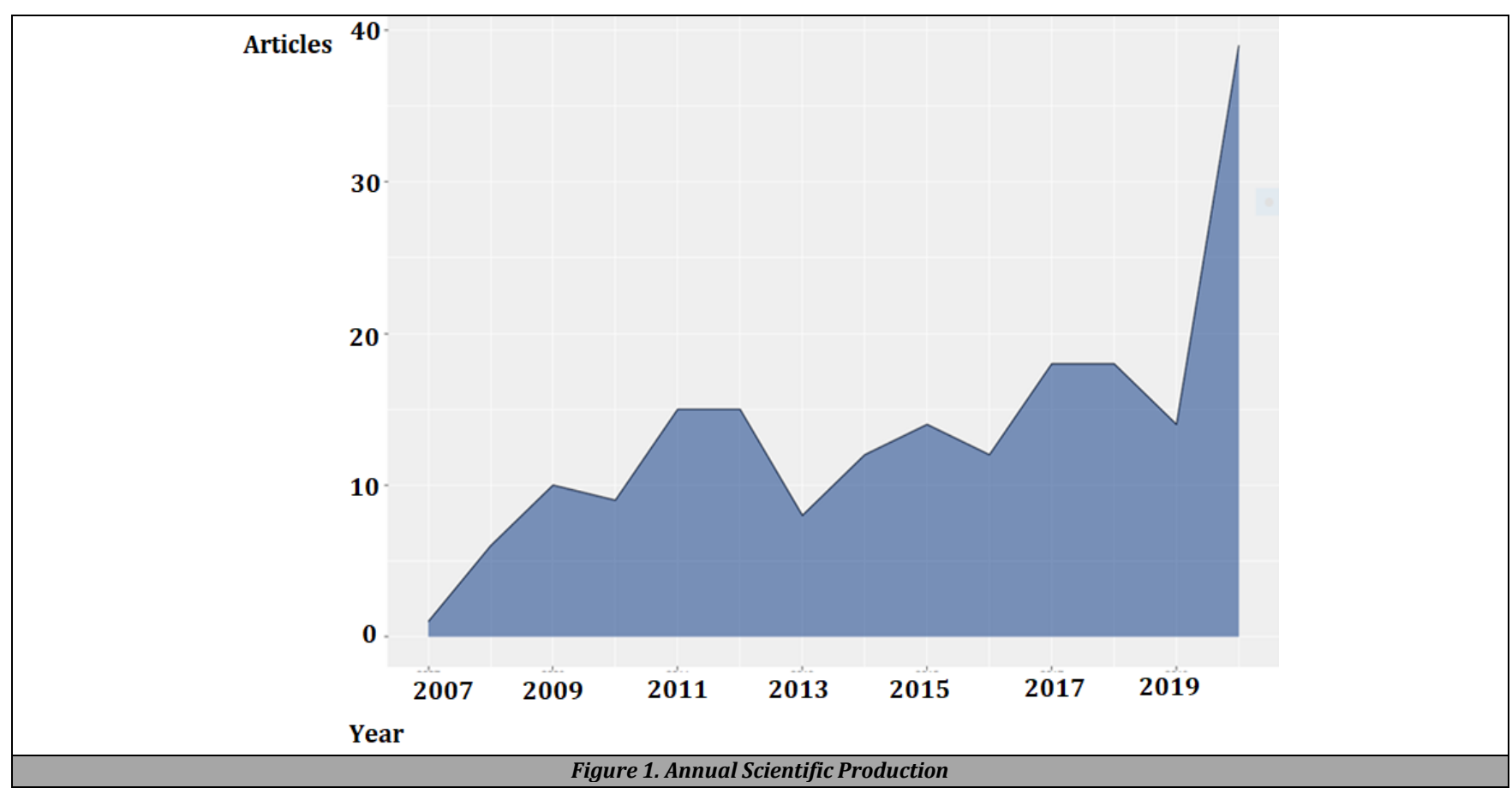




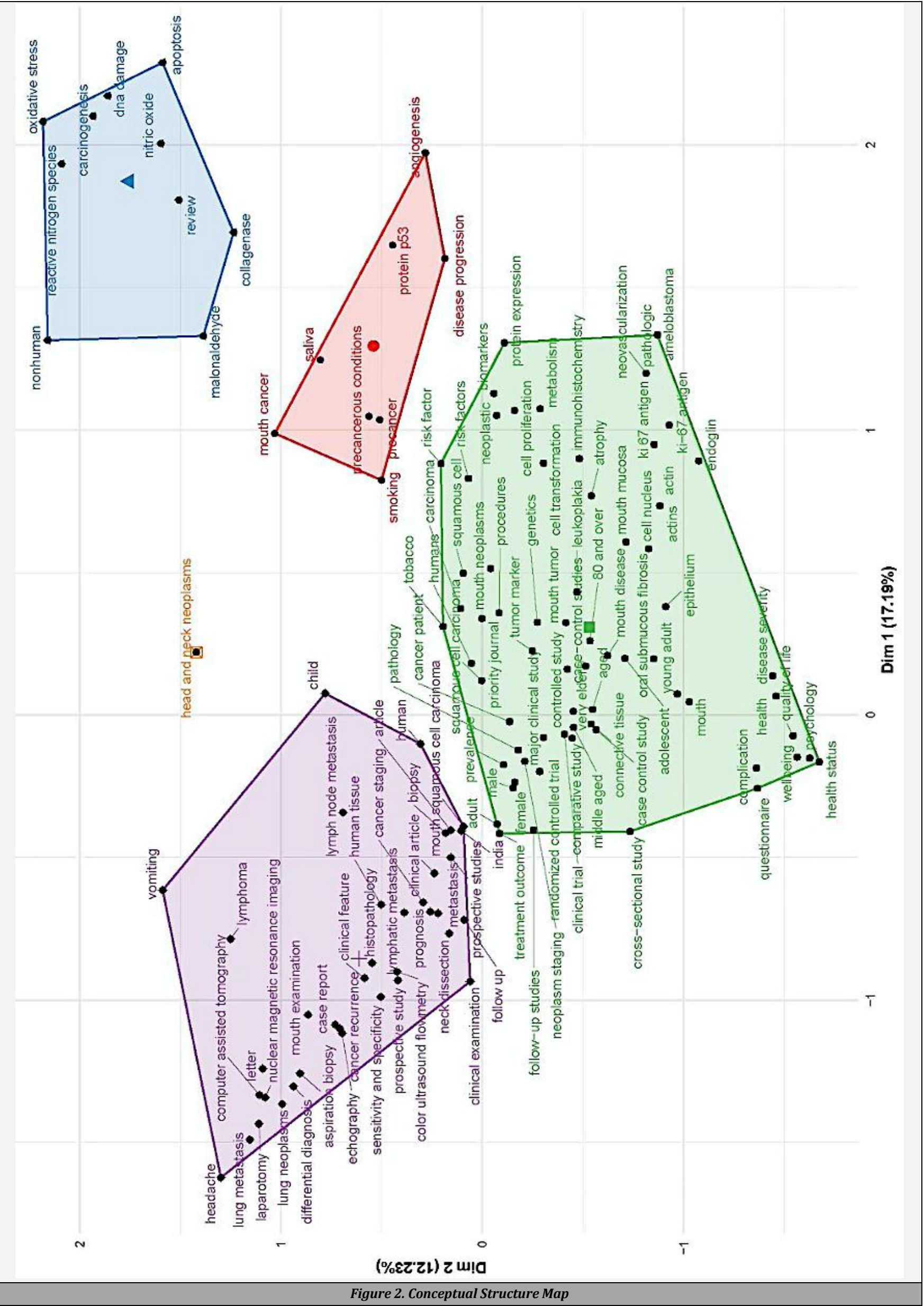




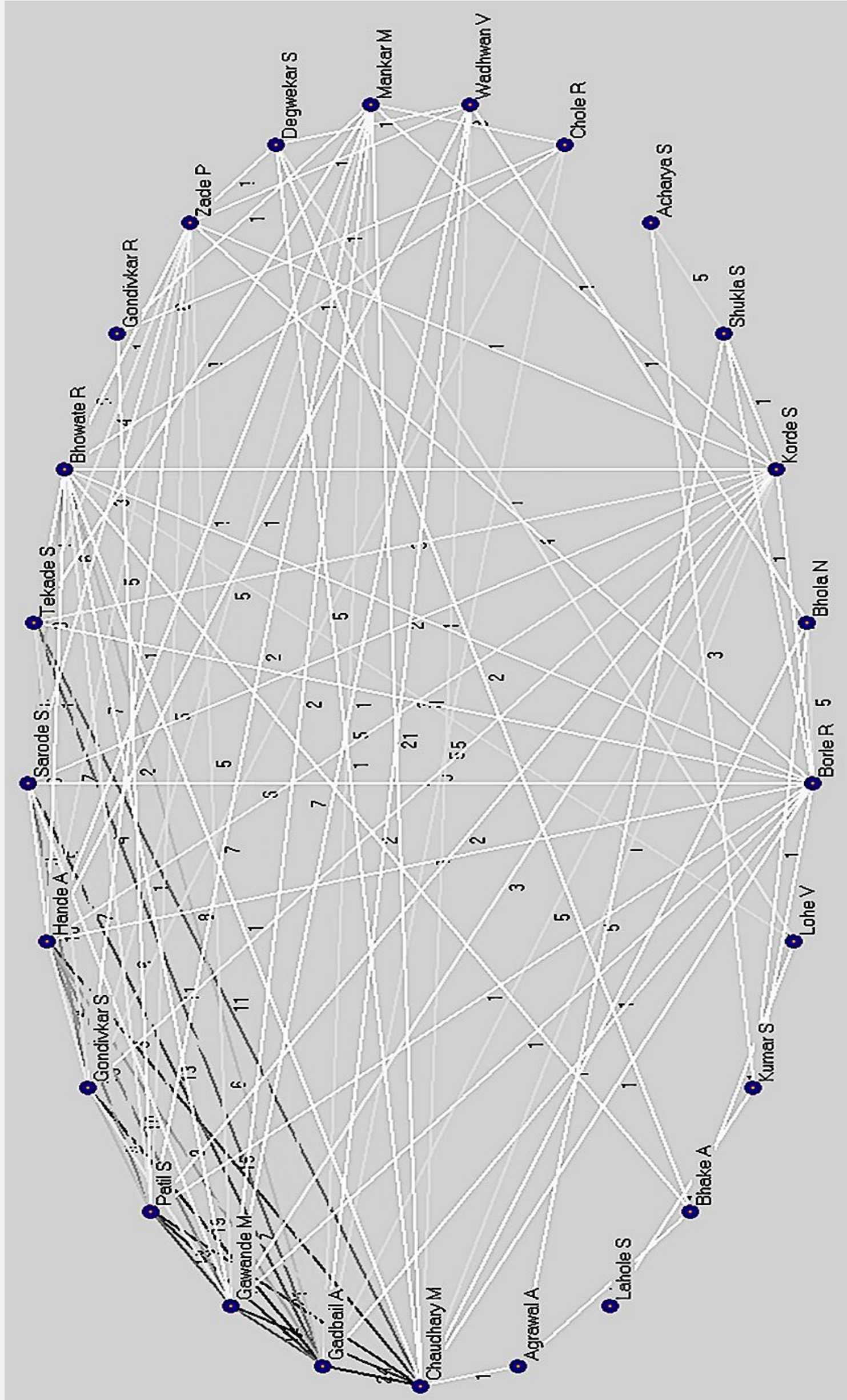


Total 30 articles were found specifically on oral submucous fibrosis and its associated factors. Majority of articles were on 'Quality of Life' in relation to oral submucous fibrosis. ${ }^{24-30}$ Five articles focused light on immunohistochemical and cytomorphometric investigations of tissues affected with oral submucous fibrosis. ${ }^{31-35}$ Role of hypoxia in malignant transformation of oral submucous fibrosis is elaborated in two articles. ${ }^{36-37}$ A retrospective study by Chourasia et al detailed on Concomitant Association of Oral Submucous Fibrosis and Oral Squamous Cell Carcinoma. ${ }^{38}$ Gadbail et al shed light on the prognosis of oral squamous cell carcinoma in the background of oral submucous fibrosis. ${ }^{39}$ Article by Borle et al details on extended nasolabial flaps in the management of oral submucous fibrosis. ${ }^{40}$

Kant et al conducted a ultrasonography and electromyography study of oral muscles in patients affected with OSMF compared to healthy individuals. ${ }^{41}$ Karemore and Motwani in their study concluded that the antioxidant called Lycopene appears as a promising drug for the management of OSMF. ${ }^{42}$ Lanjekar et al compared the efficacy of topical Curcumin gel with Triamcinolone-Hyaluronidase gel in the treatment of oral submucous fibrosis. ${ }^{43}$ Panchbhai assessed the effect of oral submucous fibrosis on jaw dimensions ${ }^{44}$ whereas Rawlani et al evaluated about the hearing impairment in OSMF patients. ${ }^{45}$ Three article detailed about dysplastic features, increased vascularity and morpho-insights of early stages of OSMF.46-48 Chole et al addressed about various drugs and vitamins ${ }^{49-50}$ whereas Yadav et al elaborated about custom made protective appliance ${ }^{51}$ for the cases of oral submucous fibrosis.

\section{CONCLUSIONS}

The university has tried to capture the available evidences on Oral Submucous Fibrosis and documented throughout the academic publications. The university has contributed significantly to the scientific literature on oral submucous fibrosis. The pattern of publications in the Health Sciences University in reputed Scopus and Web of Science is on the rise and is improving and the scope of collaborative publications with improved citations is also expected to improve in the forthcoming years.

Financial or Other Competing Interests: None.

\section{REFERENCES}

[1] Pindborg JJ, Sirsat SM. Oral submucous fibrosis. Oral Surg Oral Med Oral Pathol. 1966;22(6):764-79.

[2] Pindborg JJ, Chawla TN, Srivastava AN,. Epithelial changes in oral submucous fibrosis. Acta Odontol Scand 1965;23:277-86.

[3] Neville BW, Allen CM, Damm DD, et al. Oral and maxillofacial pathology. Philadelphia: WS Saunders Company 1995: p. 291.

[4] Gupta PC, Mehta FS, Daftary DK, et al. Incidence rates of oral cancer and natural history of oral precancerous lesions in a 10 year follow up study of Indian villagers. Community Dent Oral Epidemiol 1980;8(6):283-333.

[5] Pindborg JJ, Bhonsle RB, Murti PR, et al. Incidence and early forms of oral submucous fibrosis. Oral Surg Oral Medicine Oral Pathol 1980;50(1):40-4.

[6] Laskaris G, Bonopoulou O, Nicolis G. Oral Submucous fibrosis in a Greek female. Br J Oral Surg 1981;19(3):197201.

[7] Das M, Manjunath C, Srivastava A, et al. Epidemiology of oral submucous fibrosis: a review. Int J Oral Health Med Res 2017;3(6):126-9.

[8] Babu S, Bhat RV, Kumar PU, et al. A comparative clinic pathological study of oral submucous fibrosis in habitual chewers of pan masala and betelquid. J Clin Toxicol 1996;34(3):317-22.

[9] Sinor PN, Gupta PC, Murti PR, et al. A case-control study of oral submucous fibrosis with special reference to the etiologic role of areca nut. J Oral Pathol Med 1990;19(2):94-8.

[10] Kumar S, Mohan C, Pagrani M, et al. Submucous fibrosisrevisited. Ann Dent Spec 2014;2:14.

[11] Trivedy C, Baldwain D, Warnakulasuriya S, et al. Copper content in catechu (betel nut) products and submucous fibrosis. Lancet 1997;349(9063):1447.

[12] Nanavati S, Nanavati P, Nanavati M. Clinico-pathological study of 170 cases of submucous fibrosis. Int J Sci Study 2015;3(9):137-44.

[13] Ahmad MS, Ali SA, Ali AS, et al. Epidemiological and etiological study of oral submucous fibrosis among gutkha chewers of Patna, Bihar, India. J Indian Soc Pedod Prev Dent 2006;24(2):84-9.

[14] More CB, Das S, Patel $H$, et al. Proposed clinical classification for oral submucous fibrosis. Oral Oncol 2012;48(3):200-2.

[15] More CB, Rao NR. Proposed clinical definition for oral submucous fibrosis. J Oral Biol Craniofac Res 2019;9(4):311-4.

[16] Aziz SR. Coming to America: betel nut and oral submucous fibrosis. J Am Dent Assoc 2010;141(4):423-8.

[17] Kerr AR, Warnakulasuriya S, Mighell AJ, et al. A systematic review of medical interventions for oral submucous fibrosis and future research opportunities. Oral Dis 2011;17 Suppl 1:42-57.

[18] van der Waal I. Historical perspective and nomenclature of potentially malignant or potentially premalignant oral epithelial lesions with emphasis on leukoplakia-some suggestions for modifications. Oral Surg Oral Med Oral Pathol Oral Radiol 2018;125(6):577-81.

[19] Kumar KK, Saraswathi TR, Ranganathan K, et al. Oral submucous fibrosis: a clinico-histopathological study in Chennai. Indian J Dent Res 2007;18(3):106-11.

[20] Srinivasan M, Jewell SD. Evaluation of TGF-alpha and EGFR expression in oral leukoplakia and oral submucous fibrosis by quantitative immunohistochemistry. Oncology 2001;61(4):284-92.

[21] Chaturvedi P, Vaishampayan SS, Nair S, et al. Oral squamous cell carcinoma arising in background of oral submucous fibrosis: a clinicopathologically distinct disease. Head Neck 2013;35(10):1404-9.

[22] Kumar MS, Sarma PS, Thankappan KR. Community-based group intervention for tobacco cessation in rural Tamil 
Nadu, India: a cluster randomized trial. J Subst Abus Treat 2012;43(1):53-60.

[23] Prabhu RV, Prabhu V, Chatra L. A need to spread awareness regarding the ill effects of arecanut and its commercial products on oral health. Trop Med Surg 2014;2:3.

[24] Gondivkar SM, Bhowate RR, Gadbail AR, et al. Assessment of oral health-related quality of life instruments for oral submucous fibrosis: a systematic review using the consensus-based standards for the selection of health measurement instruments (COSMIN) checklist. Oral Oncol 2019;93:39-45.

[25] Gondivkar SM, Bhowate RR, Gadbail AR, et al. Quality of life and oral potentially malignant disorders: critical appraisal and prospects. World J Clin Oncol 2018;9(4):569.

[26] Gondivkar SM, Bhowate RR, Gadbail AR, et al. Development and validation of oral health-related quality of life measure in oral submucous fibrosis. Oral Diseases 2018;24(6):1020-28.

[27] Gondivkar SM, Bhowate RR, Gadbail AR, et al. Impact of socioeconomic inequalities on quality of life in oral submucous fibrosis patients. Future Oncol 2019;15(8):875-83.

[28] Gondivkar SM, Bhowate RR, Gadbail AR, et al. Comparison of generic and condition-specific oral health-related quality of life instruments in patients with oral submucous fibrosis. Qual Life Res 2019;28(8):2281-8.

[29] Gondivkar SM, Bhowate RR, Gadbail AR, et al. Impact of oral submucous fibrosis on oral health-related quality of life: a condition-specific ohrqol-osf instrument analysis. Oral Diseases 2018;24(8):1442-8.

[30] Gondivkar SM, Bhowate RR, Gadbail AR, et al. Quality of life-related patient-reported outcome measures in oral submucous fibrosis patients. J Contemp Dent Pract 2018;19(3):331-8.

[31] Alka HH, Prajakta ZR, Minal CS, et al. Immunohistochemical analysis of tumor-associated stroma in oral squamous cell carcinoma with and without preexisting oral submucous fibrosis. J Datta Meghe Inst Med Sci Univ 2017;12(3):170-6.

[32] Hande AH, Chaudhary MS. Cytomorphometric analysis of buccal mucosa of tobacco chewers. Rom J Morphol Embryol 2010;51(3):527-32.

[33] Gadbail AR, Chaudhary M, Sarode SC, et al. Ki67, CD105, and $\alpha$-SMA expression supports the transformation relevant dysplastic features in the atrophic epithelium of oral submucous fibrosis. PLoS One 2018;13(7):e0200171.

[34] Gadbail AR, Chaudhary MS, Sarode SC, et al. Ki67, CD105, and $\alpha$-SMA expressions better relate the binary oral epithelial dysplasia grading system of world health organization. J Oral Pathol Med 2017;46(10):921-7.

[35] Gadbail AR, Chaudhary MS, Sarode SC, et al. Ki67, CD105 and $\alpha$-Smooth muscle actin expression in disease progression model of oral submucous fibrosis. J Investig Clin Dent 2019;10(4):e12443.

[36] Chaudhary M, Bajaj S, Bohra S, et al. The domino effect: role of hypoxia in malignant transformation of oral submucous fibrosis. J Oral Maxillofac Pathol 2015;19(2):122-7.

[37] Hande AH, Chaudhary MS, Gadbail AR, et al. Role of hypoxia in malignant transformation of oral submucous fibrosis. J Datta Meghe Inst Med Sci Univ 2018;13(1):3843.

[38] Chourasia NR, Borle RM, Vastani A. Concomitant association of oral submucous fibrosis and oral squamous cell carcinoma and incidence of malignant transformation of oral submucous fibrosis in a population of central India: a retrospective study. J Maxillofac Oral Surg 2015;14(4):902-6.

[39] Gadbail AR, Chaudhary M, Gawande M, et al. Oral squamous cell carcinoma in the background of oral submucous fibrosis is a distinct clinicopathological entity with better prognosis. J Oral Pathol Med 2017;46(6):44853.

[40] Borle RM, Nimonkar PV, Rajan R. Extended nasolabial flaps in the management of oral submucous fibrosis. Br J Oral Maxillofac Surg 2009;47(5):382-5.

[41] Kant P, Bhowate RR, Sharda N. Assessment of crosssectional thickness and activity of masseter, anterior temporalis and orbicularis oris muscles in oral submucous fibrosis patients and healthy controls: an ultrasonography and electromyography study. Dentomaxillofac Radiol 2014;43(3):20130016.

[42] Karemore TV, Motwani M. Evaluation of the effect of newer antioxidant lycopene in the treatment of oral submucous fibrosis. Indian J Dent Res 2012;23(4):524-8.

[43] Lanjekar AB, Bhowate RR, Bakhle S, et al. Comparison of efficacy of topical curcumin gel with triamcinolonehyaluronidase gel individually and in combination in the treatment of oral submucous fibrosis. J Contemp Dent Pract 2020;21(1):83-90.

[44] Panchbhai A. Effect of oral submucous fibrosis on jaw dimensions. Turk J Orthod 2019;32(2):105-9.

[45] Rawlani S, Patil C, Bhowte R, et al. Evaluation of hearing impairment in oral submucous fibrosis patients. J Datta Meghe Inst Med Sci Univ 2014;9(3):151-61.

[46] Sarode SC, Chaudhary M, Gadbail A, et al. Dysplastic features relevant to malignant transformation in atrophic epithelium of oral submucous fibrosis: a preliminary study. J Oral Pathol Med 2018;47(4):410-16.

[47] Tekade SA, Chaudhary MS, Tekade SS, et al. Early stage oral submucous fibrosis is characterized by increased vascularity as opposed to advanced stages. J Clin Diagn Res 2017;11(5):ZC92-6.

[48] Hande AH, Chaudhary MS, Gawande MN, et al. Oral submucous fibrosis: an enigmatic morpho-insight. J Cancer Res Ther 2019;15(3):463-9.

[49] Chole RH, Gondivkar SM, Gadbail AR, et al. Zinc and vitamin $A$ as a low cost management of oral submucous fibrosis. Oral Oncology 2012;48(11):e46.

[50] Chole RH, Gondivkar SM, Gadbail AR, S. et al. Review of drug treatment of oral submucous fibrosis. Oral Oncol 2012;48(5):393-8.

[51] Yadav AO, Vanza BH, Borle RM, et al. Custom made protective appliance for oral submucous fibrosis. J Maxillofac Oral Surg 2013;12(4):472-4. 